
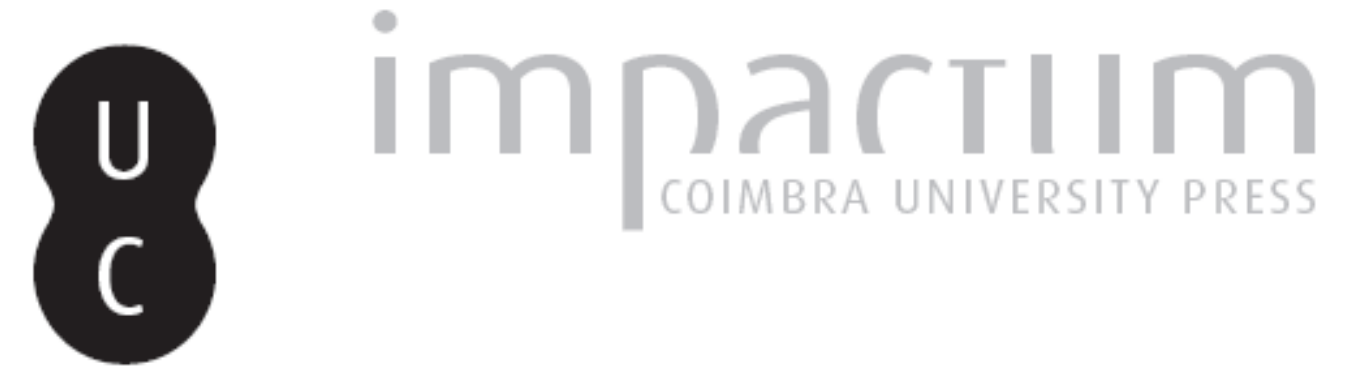

\title{
La Revolución Francesa en la obra de Tomas Ortiz
}

\section{Autor(es): $\quad$ Moliner Prada, António}

Publicado por: Imprensa da Universidade de Coimbra

URL persistente:

URl:http://hdl.handle.net/10316.2/43795

DOI:

DOI:https://doi.org/10.14195/2183-8925_10_36

Accessed : $\quad$ 26-Apr-2023 09:00:33

A navegação consulta e descarregamento dos títulos inseridos nas Bibliotecas Digitais UC Digitalis, UC Pombalina e UC Impactum, pressupõem a aceitação plena e sem reservas dos Termos e Condições de Uso destas Bibliotecas Digitais, disponíveis em https://digitalis.uc.pt/pt-pt/termos.

Conforme exposto nos referidos Termos e Condições de Uso, o descarregamento de títulos de acesso restrito requer uma licença válida de autorização devendo o utilizador aceder ao(s) documento(s) a partir de um endereço de IP da instituição detentora da supramencionada licença.

Ao utilizador é apenas permitido o descarregamento para uso pessoal, pelo que o emprego do(s) título(s) descarregado(s) para outro fim, designadamente comercial, carece de autorização do respetivo autor ou editor da obra.

Na medida em que todas as obras da UC Digitalis se encontram protegidas pelo Código do Direito de Autor e Direitos Conexos e demais legislação aplicável, toda a cópia, parcial ou total, deste documento, nos casos em que é legalmente admitida, deverá conter ou fazer-se acompanhar por este aviso.

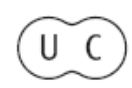


REVISTA DE HISTORIA DAS IDEIAS IO
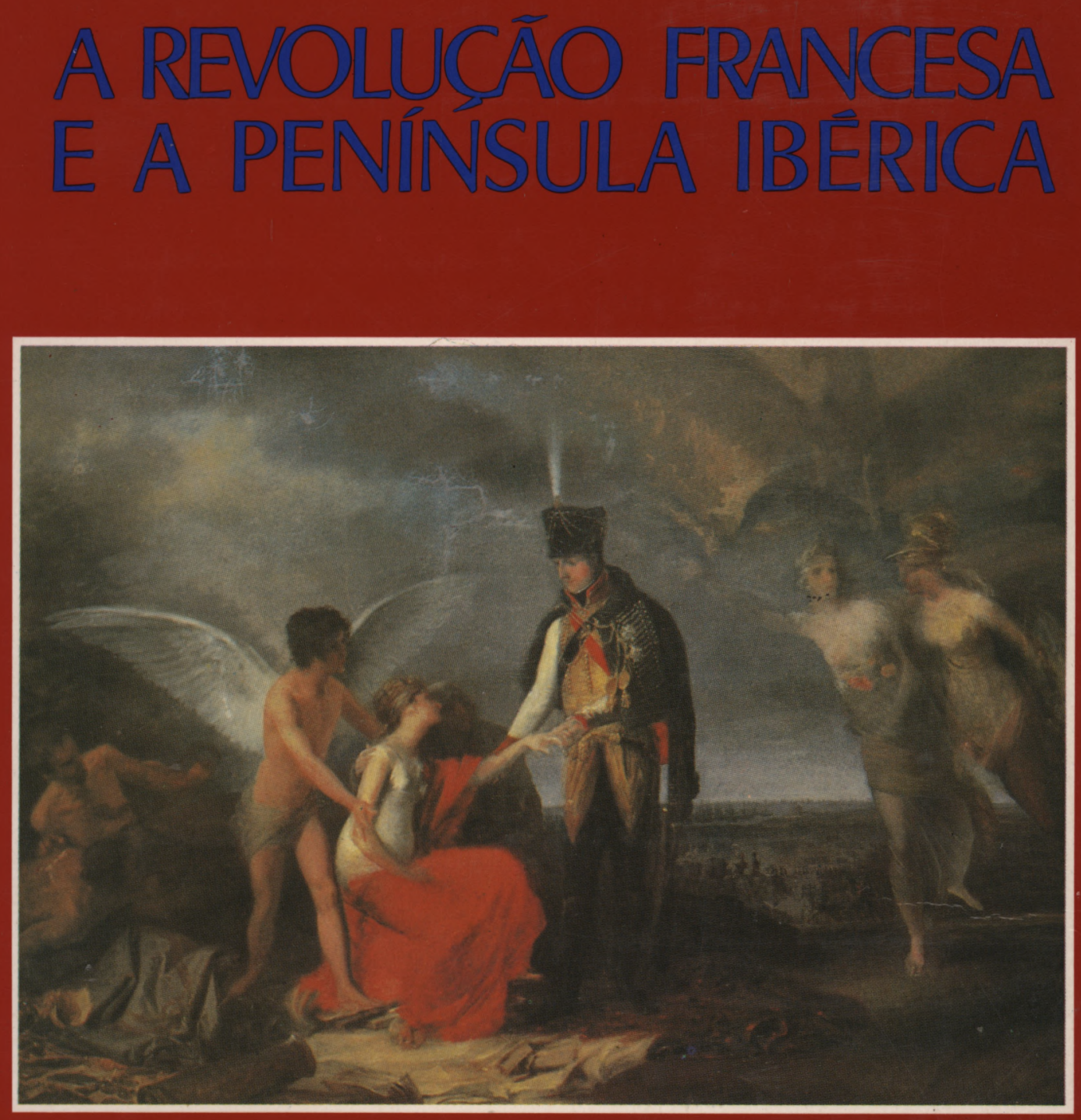

INSTITUTO DE HISTÖRIA E TEORIA DAS IDEIAS FACULDADE DE LETRAS 


\section{ANTONIO MOLINER PRADA *}

\section{LA REVOLUCIÓN FRANCESA EN LA OBRA DE TOMAS ORTIZ}

Sabemos pocos datos de D. Tomás Ortiz, autor de dos libros de texto de enseñanza primaria: Elementos de Geografía universal, dispuestos en forma de diálogo para instrucción de la juventud y Elementos de Historia Universal, arreglados para las casas de educación de ambos sexos, editados en Madrid en 1833 en la imprenta de D. Tomás Jordán, sita en la calle de Toledo ( $\left.{ }^{1}\right)$.

El autor, persona de talante liberal y relacionado con el mundo de la enseñanza, manifiesta en ambas obras una preocupación didáctica. Con el fin de resaltar los contenidos básicos y poder estar al alcance de todos, utiliza en su exposición el sistema de diálogos (preguntas y respuestas), como era usual en los catecismos de la época. Como buenos libros de texto reúnen dos características básicas: la claridad y el orden en la exposición.

Elementos de Historia Universal se inscribe dentro de la corriente del romanticismo español, que impulsó el estudio de la historia dentro de la enseñanza primaria $\left(^{(2)}\right.$.

* I. B. San Juan (Alicante).

(1) No hemos encontrado ninguna referencia de este autor en el libro de A. Palau y Dulcet Manual del librero hispanoamericano, ni en los estudios de J. Ruiz Berrio, Política escolar de España en el siglo XIX (1808-1833), Madrid, 1970, M.a C. Simón Palmer, La enseñanza primaria seglar de grado medio en Madrid (1820-1868), Madrid, 1973 y A. Viñao Frago, Política y educación en los origenes de la España contemporánea. Examen especial de sus relaciones en la enseñanza secundaria, Madrid. 1982.

(2) M. Romero Alonso, Historiografía romántica española. In trcducción al estudio de la historia en el siglo XIX, Universidad de Sevilla, Servicio de Publicaciones, 1979, pp. 242 y 257. En la Biblioteca Nacional de Madrid se conservan tres ejemplares de la obra de Tomás Ortiz (1/21307; $1 / 4288$ y $7 / 50870)$. 
La enseñanza elemental en España a principios del siglo XIX

Para el pensamiento ilustrado la educación del pueblo era el mejor instrumento para alcanzar la felicidad y el progreso social. La enseñanza debería abarcar tanto los aspectos teóricos como los prácticos con el objeto de favorecer el progreso humano. $\mathrm{Y}$ frente al carácter minoritario de la enseñanza primaria, reivindican su carácter público y gratuito. En tal sentido Cabarrús lanza la idea en 1792 de que en todos los lugares haya una o más escuelas, destinadas a enseñar a los niños a leer, escribir, contar y un catecismo político en que se comprendan los elementos de la sociedad en que viven $\mathrm{y}$ los beneficios que reciben de ella $\left(^{3}\right)$.

La herencia de los ilustrados quedó plasmada en el título IX de la Constitución de 1812 dedicado a la instrucción pública. El artículo 366 afirma taxativamente la obligación de establecer en todos los pueblos escuelas de primeras letras, «en las que se enseñará a los niños a leer, escribir y contar, y el catecismo de la religión católica que comprenderá también una breve exposición de las obligaciones civiles». Al mismo tiempo se introduce la uniformidad de la enseñanza (art. 368) y se crea una Dirección General de Estudios (art. 369). Tras la promulgación de la Constitución, se hacía necesario la elaboración de una ley general de instrucción pública que desarrollara los principios constitucionales. En este contexto hay que situar el Informe Quintana $\left({ }^{4}\right)$, que se presentó en Cádiz el 9 de septiembre de 1813. Dicho Informe constituye uno de los principales documentos donde aparecen las ideas liberales sobre la educación y se basaba en el que Condorcet presentó en 1792 a la Asamblea Nacional en nombre del Comité de Instrucción Pública (Rapport et projet de decret sur l'organisation générale de l'instruction publique) $\left(^{5}\right)$.

(3) «Carta segunda sobre los obstáculos de opinión y medio de removerlos con la circulación de luces, y sistema general de educación», en Historia de la educación en España, M.E.C., Madrid, vol. 1, 1979, p. 332 .

Sobre la situación de la enseñanza en España remito a mi artículo "La enseñanza primaria en España en-el siglo XIX», Anuario de Historia Contemporánea, Universidad de Granada (en prensa).

(4) «Informe de la Junta creada por la Regencia para proponer los medios de proceder al arreglo de los diversos ramos de Instrucción Pública. Por Quintana", en Historia de la Educación en España, ob. cit., vol. 1, pp. 373-414.

Sobre la comisión encargada de la redacción de este Informe y la actuación de Quintana, A. Dérozier, Manuel José Quintana y el na. cimiento del liberalismo en España, Madrid, 1978, pp. 702 y ss.

(5) M. Puelles Benitez, Educación e ideología en la España contemporárea (1767-1975), Barcelona, 1980, pp. 61-62. 
El Informe parte de que la educación es el mejor método para conseguir el progreso social. Las bases generales de toda enseñanza serían las siguientes: $1 .^{\mathrm{a}}$ ) la instrucción debe ser tan igual y tan completa como las circunstancias lo permitan; $\left.2 .^{a}\right)$ la instrucción por tanto, debe ser universal y extenderse a todos lcs ciudadanos; $3 .^{\mathrm{a}}$ ) el plan de enseñanza debe ser uniforme en cuanto a métodos, libros de texto, lengua castellana, etc.; $4 .^{\mathrm{a}}$ ) la enseñanza será pública, abierta a todos; $5 .^{\mathrm{a}}$ ) la enseñanza debe ser gratuita, principalmente la escuela de primeras letras, y $6 .^{\text {a) }}$ la enseñanza debe ser libre (libertad de elección de centro).

Con el retorno al absolutismo en 1814 se olvidó dicho Informe y no se convirtió en norma legal, aunque con modificaciones, hasta 1821.

Respecto a la enseñanza secundaria, si bien no fue hasta el llamado Plan Pidal de 1845 cuando se reglamentó en España este nivel, que adquirió un cariz específico con la creación de Institutos, desde finales del siglo XVIII y principios del XIX asistimos a unos tímidos planteamientos en este sentido $\left({ }^{6}\right)$.

Fruto de la ideología ilustrada fueron los diversos centros docentes que se crearon a finales del siglo XVIII, como el Seminario de Nobles, los Reales Estudios de San Isidro, el Real Instituto Militar Pestalozziano, el Real Instituto Asturiano, etc., con el objeto de abrir nuevos caminos, poniendo el acento en las disciplinas utilitarias frente a la enseñanza tradicional del Antiguo Régimen.

Sin embargo los obstáculos que había que superar eran tales que los proyectos ilustrados se quedaron a medio camino, no consiguiendo reformar las Facultades de Artes ni el control sobre las Escuelas de Latinidad y Gramática o los mismos Seminarios. A. Viñao Frago señala la debilidad de las bases materiales y financieras en que se apoyaron las actuaciones educativas de los ilustrados, por su dispersión e insuficiente voluntad de llevarlas a cabo $\left(^{7}\right)$.

El periodo de la guerra de la Independencia posibilitó la introducción, por lo menos teórica, de un nuevo sistema educativo en ambos bandos.

(6) El libro de A. Viñao Frago, ya citado, es imprescindible para tener una visión general de este nivel de enseñanza. Para el caso del País Valenciano es interesante el libro de Angels Martínez Bonafé Ensenyament, burguesia $i$ liberalisme. L'ensenyament secundari en els origens del País Valencid contemporani, Valencia, 1985, centrado priñcipalmente en el análisis del Instituto Provincial de Segunda Enseñanza de Valencia.

(7) A. Viñao Frago, ob. cit., p. 469. 
La obra educativa del gobierno de José Bonaparte estaba dirigida a crear un sistema de educación secundaria clásica y general para todo el país: el establecimiento de liceos provinciales en cada capital de provincia, imitando la ley francesa de creación de liceos de 1 de mayo de 1802.

Aunque el texto constitucional de 1812 no alude a este nivel de enseñanza directamente, sí está contemplado en el Informe Quintana y en el Dictamen y proyecto de decreto sobre el arreglo general de la Enseñanza Pública (7 marzo 1814).

Según el Informe el objetivo de la segunda enseñanza es

"preparar el entendimiento de los discípulos para entrar en el estudio de aquellas ciencias, que son en la vida civil el objeto de una profesión liberal, y el sembrar en sus ánimos la semilla de todos los conocimientos útiles y agradables que constituyen la ilustración general de una nación civilizada» $\left({ }^{8}\right)$.

Las materias de estudio se dividen en tres grupos: ciencias matemáticas y físicas; ciencias morales y políticas, y literatura y artes.

La historia aparece unida a la enseñanza de la literatura:

«En primer lugar porque no hay ninguna disparidad repugnante entre las dos, en segundo, por el atractivo que tiene el estudio de la historia, y por su facilidad para los que ya han formado y enriquecido su entendimiento con los conocimientos anteriores; en tercero, en fin, por la necesidad que había en nuestro dictamen de economizar cátedras en establecimientos que han de multiplicarse tanto como las universidades de provincia. Movidos de estas consideraciones, hemos creido conciliarlo todo proponiendo que los elementos de la historia general, ó el cuadro en grande de las revoluciones, de los imperios y de la civilización de las naciones del mundo, sea lo que termine el estudio de la literatura y esté a cargo de los mismos profesores» ${ }^{(}{ }^{9}$.

Por su parte, según el Dictamen la segunda enseñanza «debe abrazar los conocimientos generales que constituyen la civilización de una Nación, y preparan a los adultos para todas las ocupaciones de la vida social, y para entrar con aprovechamiento al cultivo de una ciencia o arte particular» $\left({ }^{10}\right)$. Man-

(8) «Informe de la Junta....», ob. cit., en Historia de la Educación en España, vol. 1, pp. 385-386.

(9) "Informe de la Junta....», ob. cit., p. 391.

(10) «Dictamen y proyecto de decreto sobre el arreglo general de la enseñanza pública presentados a las Cortes por su comisión de Instrucción Pública y mandados imprimir de orden de las mismas» (7 marzo de 1814). 
tiene también la misma división de materias y la unión de la literatura y de la historia, asignaturas que se impartirían durante dos cursos.

Tras 1814, de nuevo se puso en vigor el Plan Caballero de 1807. Situación que cambiaría durante el Trienio Liberal.

El nuevo Reglamento de Instrucción Pública, aprobado por decreto de las Cortes el 29 de junio de 1821, establecía los principios de enseñanza pública, universal, uniforme y gratuita, y decretaba la libertad de enseñanza.

La enseñanza quedaba estructurada en tres grados. La primera enseñanza, esencial y básica, indispensable para toda la infancia, se impartiría en las escuelas públicas. Suponía la puesta en práctica del ideario liberal.

Respecto a la segunda enseñanza, dicho Reglamento era una reelaboración del proyecto de 1814 con las modificaciones acordadas por la Comisión de Instrucción Pública. También aquí permanecían unidas las materias de literatura e historia. Este nivel de enseñanza comprendía «aquellos conocimientos que al mismo tiempo que sirven de preparación para dedicarse después a otros estudios más profundos, constituyen la civilización general de una Nación» (11). El artículo 27 señalaba expresamente que el Gobierno se encargaría de promover eficazmente la publicación de obras elementales a propósito para la enseñanza de la juventud $\left(^{(2)}\right.$.

De nuevo, los problemas financieros, las divisiones internas entre moderados y exaltados y otras causas externas, encerraron la actuación liberal en materia educativa en un callejón sin salida. A. Viñao Frago resume con estas palabras la actuación educativa durante el Trienio Liberal:

"En conclusión, bien por causas externas o internas al
mismo sistema liberal, bien por la escasa duración de este
periodo, los rasgos que definen estos tres años son los de
irrealidad, impotencia, incapacidad, ineficacia y casi nula
actuación práctica, resumidos todos ellos en ese «no pode-
mos» de Alcalá Galiano pronunciado al discutirse en las
Cortes el presupuesto de instrucción pública para 1822-1823,
y concretados en la falta de medios financieros (por man-
tener el principio de gratuidad), materiales (por no recurrir
a la utilización de edificios religiosos para establecer los
nuevos establecimientos docentes) y personales (por la
imposibilidad de disponer de un número suficiente de pro-

(11) «Reglamento general de Instrucción Pública, aprobado por las Cortes el 29 de junio de 1821", en Historia de la Educación en España, vol. II, p. 46.

(12) «Reglamento general....», ob. cit., p. 46. 


\section{Revista de História das Ideias}

fesores en las disciplinas fijadas por el Reglamento de 1821). Lo interesante de esta primera experiencia sería precisamente ese carácter de ensayo o prueba, que ilustraría en épocas posteriores a quienes intentasen llevar a la práctica el ideario educativo liberal, para tratar de corregir los errores precedentes, y, por su influencia en el desarrollo posterior de la enseñanza secundaria y de sus planes de estudio, la actuación (propiciada por esa misma ineficacia del sector público docente) de A. Lista en el campo de la enseñanza privada seglar, que corregía, acentuando los aspectos literarios-humanísticos, la orientación científico-utilitaria de los primeros planes de estudio liberales» (13).

Tras 1823 el nivel educativo de segunda enseñanza conoció en 1826 un intento de reorganización dentro del sistema tradicional, al aprobarse el Reglamento general para las Escuelas de Latinidad y Colegios de Humanidades, firmado por Tadeo Calomarde, ministro de Gracia y Justicia.

En este contexto hay que situar la obra de Tomás Ortiz. Elementos de Historia Universal es un libro de texto de nivel elemental para ser utilizado en las casas de educación de ambos sexos, establecimientos docentes que reciben este nombre y surgieron en Madrid durante el Trieno Liberal.

Dichos colegios tenían alumnos internos y externos y estaban dirigidos por particulares. Los profesores cobraban honorarios relativamente altos, comparativamente con otros centros, y allí acudían los hijos de gente acomodada que no poseían títulos nobiliarios. Entre estos colegios destacaron los de niños dirigidos por José Garriga y Alberto Lista y el de niñas por Juan Kearney y su mujer ${ }^{\left({ }^{14}\right)}$. En ellos se ofrecía un tipo de enseñanza más brillante que en el resto de escuelas, con el objeto de que los niños consiguieran atraer la atención de los demás para poder destacar en sociedad $\left({ }^{15}\right)$.

Tras los años del Trienio Liberal, la comisión regia que elaboró el plan llamado de Calomarde, solicitó informes al corregidor sobre estos colegios a casas llamadas «pensiones de educación». Éste designó a tal efecto una comisión que informó negativamente, alegando las siguientes razones: el espíritu de negocio de los empresarios de estos centros, el excesivo número de profesores existentes (sobre todo de idiomas), el uso de libros extranjeros y el hecho de que varios profesores y directores fueran «afrancesados» $\left({ }^{16}\right)$.

(13) A. Viñao Frago, ob. cit., p. 472.

(14) A. Ruiz Berrio, ob. cit., pp. 188 y ss.

(15) M. Romero Alonso, ob. cit., p. 256.

(16) J. Ruiz Berrio, ob. cit., pp. 188-189. 


\section{La Revolución Francesa en la Obra de Tomas Ortiz}

Las razones reales del ataque a estos centros eran porque quitaban alumnos a los antiguos colegios de Madrid y porque sus directores eran adictos al sistema canstitucional. Sin embargo, se autorizó después a José Garriga para que pudiera continuar abierto su colegio y a Lista se le concedió el permiso necesario para poder impartir clases particulares $\left({ }^{17}\right)$. A partir de 1827 sólo se habían cerrado algunos de estos colegios, continuando estas casas con el nombre de Colegios de Humanidades.

En este tipo de escuelas se formaron los grandes historiadores y literatos del siglo XIX. Debemos destacar la meritoria labor llevada a cabo por Alberto Lista, como director de estudios del colegio de San Mateo, abierto en abril de 1821, y profesor de matemáticas y ciencias políticas. El plan de estudios por él elaborado daba importancia tanto a la educación moral o religiosa como a la educación literaria, a la educación física y a la urbanidad. Las materias impartidas se agrupaban en tres bloques: 1) lenguas (latina, griega, castellana y francesa); 2) mitología. geografía, cronología e historia, y 3) elocuencia y poética. La estancia de los colegiales se calculaba en unos ocho años, de forma que al salir pudieran emprender cualquier estudio superior $\left(^{18}\right)$.

Fue precisamente en estos centros donde se dio una gran importancia a los estudios de historia, de forma que proliferaron mucho los libros de texto.

Elementos de Historia Universal de Tomás Ortiz se utilizaba como libro de texto en el colegio de José Garriga junto con los de Goldmisth e Iriarte. Dicha materia se impartía durante una hora tres días a la semana. Según el Reglamento de

(17) J. Ruiz Berrio, ob. cit., p. 189.

(18) M. ${ }^{2}$ C. Ruiz Berrio, ob. cit., pp. 191-192. Sobre la destacada actuación de Alberto Lista: H. Juretschke, Vida, obra y pensamiento de Alberto Lista, Madrid, 1951 y M. Ruiz Lagos, Ilustrados y reformadores cn la baja Andalúcia, Madrid, 1974, pp. 166 y ss.

El historiador V. de la Fuente elogiaba su labor con estas palabras: "También adquirió nombradía por entonces el Colegio de la calle de San Mateo, bajo la dirección de don Alberto Lista, en que se educaron bajo su acertada dirección muchos de los jóvenes que luego se hicieron célebres, de 1834 en adelante, en política y literatura. En sus biografías se hallan datos dispersos acerca de esos establecimientos en que parcialmente se formaron, y más en el de don Alberto Lista». Cfr. Historia de las Universidades, Colegios y demás establecimientos, vol. IV, p. 373, citado por M. Romero Alonso, ob. cit., pp. 256-257.

Es de interés el artículo de $\mathbf{M}^{2}$ del C. Simón Palmer sobre el colegio de San Mateo, Cfr. "El Colegio de San Mateo (1821-1825)», en Arales del Instituto de Estudios Madrileños, vol. IV (1868), pp. 1-53. 
este centro el objetivo del estudio de la historia era conocer los usos, costumbres y la legislación de un país:

\begin{abstract}
«Esta parte se despojará cuando sea posible de lo que no se da conocer más que el destrozo de los estados y la ambición de ciertos hombres singulares, y se procurará dar a los niños idea de costumbres, usos, legislación y demás cosas que han conducido las sociedades al estado en que se hallan, y que puede perfeccionar las instituciones, usos y costumbres de nuestro país. Se procurará que la historia sea para los niños una lección útil, no la lectura de hechos estériles» (19).
\end{abstract}

(19) M.a C. Simón Palmer, ob. cit., p. 189. Como apunta M. Romero Alonso, nunca como en el romanticismo proliferaron tantos los libros de texto, con una clara preocupación didáctica: "Partiendo de la nada, por consiguiente, nuestro romanticismo, podemos decir, creó en lo que a la historia se refiere, la noción de libro de texto, no sólo aplicado a lo que se va a llamar la enseñanza primaria o instrucción primaria sino también a la secundaria y enseñanza superior o universitaria». Cfr. ob. cit., p. 259.

Entre los estudios de historia, adaptados a las primeras letras, el citado autor señala los siguientes:

- Compendio de la historia de España desde los tiempos más remotos hasta 1829. Escrito en forma de diálogo para el uso de los niños. Por J.M. Antequera, Madrid, libr. A. González, 1848, 204 pp.

- Compendio de Historia de España, para uso de las escuelas de enseñanza primaria y superior. Por D. Miguel Araño, Barcelona, 1858 (5." edc.), 88 pp.

- Breves nociones en compendio de la historia de España, para uso de los niños de educación primaria, por D.F.R. Briones, Madrid, $1835,24 \mathrm{pp}$.

- Compendio dialogado de la historia de España, desde los tiempos primitivos hasta nuestros dias. Por M. Caballero de Rodas, impt. de J. González, 1857, 176 pp.

- Compendio de historia antigua y moderna, para uso de escuelas $y$ colegios. Paris, impt. de Pillet, 1840.

- Compendio de Historia de España por G. de la Escosura, Madrid I. Boix, 1839.

- Elementos de historia y cronología de España para uso de los niños. Por A. Gómez, Madrid, 1843.

- Compendio de la historia de España desde la más remota antiguedad hasta el presente, por I.F. Monje y T. Hurtado, Madrid, 1858, $130 \mathrm{pp}$.

- Brevisima reseña de la historia de España destinada para los alumnos de la escuela pública de Tarrasa, por un profesor. Por P. Payeras, Barcelona, 1857.

- Compendio de la historia de España, escrita en forma de diálogo para uso de los niños. Por P. Pérez, Valencia impt. de J.M. Cervera, 1842.

- Manual de historia universal antigua y moderna. Obra elemental para uso de los niños. Por A.G. Ranera Madrid, impt. Gómez, 1845, etc. (La mayor parte de estos libros tienen una preocupación 


\section{La obra de Tomás Ortiz}

Elementos de Historia Universal es un compendio de Historia desde la antigüedad hasta los tiempos modernos. La Historia es concebida como «el conocimiento del origen, progresos, leyes, usos y costumbres de las diferentes naciones que han poblado el mundo en los siglos antiguos y modernos» $\left({ }^{20}\right)$. Ésta se divide en sagrada y profana. Mientras la historia sagrada trata del pueblo de Dios y de la fundación del cristianismo, la profana estudia la historia de las demás naciones, «conservada y transmitida por los monumentos, por la tradición y por los libros de los historiadores» $\left({ }^{21}\right)$.

La utilidad de la historia profana se fundamenta en cinco razones principales: $1 .^{a}$ ) nos enseña el origen y progresos de los imperios, así como las causas de su ruina y de su prosperidad; $2 .^{a}$ ) nos manifiesta el carácter de los pueblos, las virtudes y los vicios de los hombres que las han gobernado; $3 .^{\mathrm{a}}$ ) nos instruye en el origen y progresos de las ciencias y artes y en los adelantos que los hombres han hecho en la carrera de la civilización; $4 .{ }^{a}$ ) confirma la verdad de la historia sagrada, y $\left.5 .^{a}\right)$ manifiesta los secretos juicios de Dios y los altos fines de la Providencia ${ }^{22}$ ).

Mientras la historia antigua estudia los primeros imperios que se fundaron en el mundo hasta Carlomagno, la historia moderna se extiende desde el siglo IX hasta la época presente.

Tras describir el imperio de los egipcios (gobierno, religión, costumbres, reyes y tabla cronológica), analiza la historia de Cartago y los imperios de los asirios, medos, lidios, persas y macedonios, finalizando con Grecia y Roma.

La historia moderna contiene dos partes: la primera se extiende desde Carlomagno hasta el reinado de Carlos V de Austria, la segunda desde este reinado hasta los tiempos actuales.

La primera época de la historia moderna la sitúa entre el año 800 y el 962; la segunda desde el 962 (creación del Imperio de Alemania) al 1074; la tercera abarca la historia de las cruzadas (1074 al 1300), y la cuarta desde el 1300 hasta la caída de Constantinopla, coincidiendo con el período más fructífero para la humanidad (pintura al óleo, imprenta, pólvora, brújula y desarrollo comercial).

didáctica, utilizando para ello en su exposición la forma de diálogos en verso, el cuento o la simple narración pintoresca).

(20) T. Ortiz, Elementos de Historia Universal, ob. cit., p. 3.

(El autor identifica el concepto de historia con el de civilización, siguiendo a los ilustrados franceses).

(21) T. Ortiz, ob. cit., p. 4.

(22) T. Ortiz, ob. cit., p. 4. 


\section{Revista de História das Ideias}

La segunda época de la historia moderna ha sido la más fecunda en sucesos importantes: el descubrimiento de América, la reforma del cristianismo, el renacimiento de las letras, el establecimiento de las dinastías actuales y el reinado de Napoleón Bonaparte $\left({ }^{23}\right)$. Ésta abarca cuatro pericdos: el primero desde 1453 hasta 1648; el segundo, desde 1648 a 1713; el tercero, desde 1713 hasta 1789 , y el cuarto, desde 1789 hasta 1804.

El engrandecimiento de Francia se forjó durante el reinado de Luis XIV:

"Todo el sistema político de Europa mudó de aspecto al principio de este periodo de resultas de la preponderancia que la Francia empezó a adquirir en los reinados de Carlos VII y de Luis XI.... A mediados del siglo XV quedó afianzado su predominio por la buena administración de la hacienda pública, el incremento que tomaron el comercio, la industria y la marina. Luis XIV fue el que aseguró a la Francia su superioridad en la balanza política.... Ay:dado por su ministro Colbert, Luis XIV protegió con el más incansable empeño las artes, las ciencias y las letras» (24).

\section{La Revolución francesa}

El origen de la Revolución francesa, según Tomás Ortiz, hay que relacionarlo con la difícil situación hacendística del país en tiempos de Luis XVI. La nación se hallaba gravada con una deuda considerable, además del déficit anual. Ante tales necesidades, y la negativa de los nobles a una reforma fiscal, sólo los Estados Generales podían conceder arbitrios y contribuciones para solucionar el problema hacendístico. Necker, ministro de Hacienda, persuadió al Rey que convocase los Estados Generales, concediendo al tercer estado un número de diputados igual a la suma de los del clero y nobleza. Empezaron las elecciones y con ellas la Revolución $\left({ }^{25}\right)$.

Dos hechos marcan el principio de la Revolución: la constitución de la Asamblea Nacional y la destitución de Necker. Tras la convocatoria de los Estados Generales el 5 de mayo, el tercer estado, «más unido y compacto que los otros dos, exigió que se reuniesen todos en una cámara para el examen de los poderes». Ante la negativa del clero y de la nobleza, se constituyeron en Asamblea Nacional. Tras ordenar el Rey suspender sus sesiones, los diputados se reunieron en el Juego

(23) T. Ortiz, ob. cit., p. 256.

(24) T. Ortiz, ob. cit., pp. 285-286.

(25) T. Ortiz, ob. cit., pp. 312-313. 


\section{La Revolución Francesa en la Obra de Tomas Ortiz}

de Pelota de Versalles y juraron no separarse hasta haber concluido la reforma de gobierno $\left({ }^{\mathbf{2 6}}\right)$.

En segundo lugar, el Rey reunió a un ejército cerca de Versalles y destituyó a Necker. Ello motivó la sublevación del pueblo de París, que demolió la Bastilla, prisión de los reos del Estado, se apoderó de los depósitos de armas, adoptó la cucarda tricolor, estableció un cuerpo municipal y organizó una guardia nacional mandada por el general Lafayette. Después Necker volvió al ministerio $\left({ }^{27}\right)$.

Tras el estallido de la Revolución la Asamblea Nacional se apoderó de todos los poderes y empezó a formar una constitución, aboliéndose los derechos feudales, los privilegios de las provincias y ctras muchas instituciones.

Nobles y clérigos se vieron sometidos a los «excesos» del pueblo, exiliándose la mayor parte de ellos a otros países.

El Rey, que huyó de París, fue descubierto en Varennes y llevado preso a la capital. Hecho que pone fin a la primera etapa de la Revolución.

La segunda etapa de la Revolución comienza tras el tratado de Pilnitz, entre el emperador Leopoldo y Prusia, por el que obligaba a restituir a Luis XVI en su trono con plena autoridad. A la Asamblea Constituyente le sucedió la Legislativa. Dicha Asamblea se dividió en dos partidos, el de la derecha, favorable a los intereses del trono, y el de la izquierda que aspiraba a la república $\left({ }^{28}\right)$.

Tomás Ortiz destaca la labor de sedición llevada a cabo por los jacobinos en los arrabales de Päís:

«P. Continuad la historia de la revolución francesa después de la división de la asamblea.

R. El pueblo entró en las Tullerías, y el rey se negó a sancionar todo lo que se le exigiera con medios violentos. Petion y sus partidarios pidieron la destitución del rey. El pueblo atacó el palacio, y el rey huyó a la asamblea. v se puso bajo su protección. Los suizos de la g:ardia murieron defendiendo las Tullerías. La asamblea decretó la destitיción del rey, su prisión y la de toda su familia, y la reunión de una convención nacional» (29).

Estas «sangrientas escenas» duraron tres días, siendo presos y asesinados los ncibles y clérigos que había en París, ejerciendo así el ayuntamiento y los ministros nombrados por la Asamblea un poder sin límites $\left({ }^{30}\right)$.

(26) T. Ortiz, ob. cit., p. 313.

(27) T. Ortiz, ob. cit., pp. 313-314.

(28) T. Ortiz, ob. cit., p. 315.

(29) T. Ortiz, ob. cit., p. 325.

(30) T. Ortiz, ob. cit., p. 317. 


\section{Revista de História das Ideias}

La tercera fase de la Revolución se sitúa con la reunión de la Convención Nacional que sustituyó a la Asamblea Legislativa. Entre sus actuaciones hay que destacar la abolición de la dignidad real, la creación de la República, la proscripción de los emigrados y el encausamiento contra Luis XVI, a pesar de los esfuerzos del partido de la Gironda por salvarlo: «Aquel desventurado monarca - comenta el autor - perdió la vida en el cadalso con la serenidad de un héroe y con la resignación de un cristiano» $\left({ }^{31}\right)$.

El partido de la «Montaña» estaba compuesto por hombres «sanguinarios y ambiciosos». Tras dominar a los girondinos, establecieron una Junta de Salud Pública que ejerció el poder sin límites: «Entonces se restableció el régimen de terror, durante el cual perecieron innumerables víctimas en los cadalsos. Robespierre, jefe de esta facción, cubrió a la Francia de sangre y de desórdenes. La reina, el duque de Orleans y los diputados girondistas fueron condenados a muerte. La Junta abolió el calendario gregoriano y la religión cristiana» ${ }^{\mathbf{3 2}}$ ).

El autor destaca la reacción de los realistas contra los republicanos, la guerra de la Vendée, así como los levantamientos de Burdeos y Marsella y las coaliciones de las potencias europeas contra Francia. En el sitio de Toulon se distinguió por su valor y entusiasmo «republicano» el joven oficial de artillería Napoleón Bonaparte.

Durante esta etapa revolucionaria tres eran los grupos o partidos más importantes: el de la Junta de Salud Pública, que tenía un poder absoluto bajo el dominio de Robespierre; el de la municipalidad de París (sin ningún recurso para hacerle frente, pero más violento aún), y el de Danton y sus amigos que aspiraba a destruir a los anteriores, aunque muchos de sus partidarios murieron en el cadalso $\left({ }^{33}\right)$.

La radicalidad de Robespierre le llevó a su misma destrucción:

«P. Continuad la historia de la revolución francesa después de la muerte de Danton.

R. Robespierre no gozó mucho tiempo de su triunfo. El tribunal revolucionario, que le servía de instrumento para condenar a muerte a sus enemigos, fue revestido de facultades ilimitadas. Entonces conocieron algunos miembros de la convención que iban a ser víctimas del tirano, y resol-

(31) T. Ortiz, ob. cit., p. 316.

(32) T. Ortiz, ob. cit., pp. 316-317.

(33) T. Ortiz, ob. cit., p. 317. 


\title{
La Revolución Francesa en la Obra de Tomas Ortiz
}

\begin{abstract}
vieron abatir su poder. Tallen y otros oradores le atacaron en la tribuna. El escapó al ayuntamiento, compuesto de sus hechuras. Armáronse los dos partidos: Robespierre, declarado fuera de la ley, quiso matar-se, pero no hizo mas que romperse una mandíbula. Al día siguiente fue guillotinado con venticino de sus cómplices. Otros ochenta y tres lo fueron dos días después. El terror disminuyó entonces; salieron millares de víctimas de las cárceles; mas no cesaron por esto las violencias y las persecuciones» (34).
\end{abstract}

Con la derrota del partido de Robespierre y tras su aniquilación física, la Revolución se introduce por nuevos derroteros. Esta etapa corresponde al Directorio bajo el dominio de los moderados que introdujeron una nueva constitución, cuyos aspectos más sobresalientes eran las dos cámaras y el poder ejecutivo compuesto por cinco miembros. Las medidas tomadas sobre la reelección de un cierto número de diputados disgustó al pueblo de París que fue vencido por las fuerzas de la Convención mandadas por el general Bonaparte.

Promulgada la nueva constitución, quedaron instalados el cuerpo legislativo y el Directorio ejecutivo. Durante este periodo los problemas fundamentales eran el desorden existente y la penuria de la Hacienda. Tanto el Directorio como el cuerpo legislativo estabán divididos en dos grupos, moderados y revolucionarios: «Este logró vencer a sus enemigos, desterrando dos miembros del directorio, sesenta y cinco diputados y los escritores moderados y realistas» $\left.{ }^{(35}\right)$.

Las gestas de Napoleón durante el Directorio son descritas con profusión: la ocupación de la Lombardía, las batallas de Castiglione, la paz de Leoben, la campaña de Egipto, etc. Tras apoderarse los turcos de Abukir, ante la falta de socorros, Napoleón se trasladó a Francia, desembarcando en Provenza.

El descontento era general en muchas provincias. El Consejo de los Quinientos preparaba medidas revolucionarias, mientras en el oeste se había organizado una nueva sublevación, mandada por Georges. Por su parte Barras y Sieyès querían cada uno de ellos valerse del influjo de Napoleón. Éste conspiró con Sieyès y con los principales miembros del Consejo de los Ancianos. El Consejo le nombró comandante de las tropas, destituyó al Directorio y trasladó el cuerpo legislativo a Saint Cloud. Tras abolir la constitución se estableció un gobierno provisional, compuesto por Roger Ducos y Bonaparte, y se nombró una nueva comisión para formar el proyecto de una nueva constitución ${ }^{\left({ }^{36}\right)}$.

(34) T. Ortiz, ob. cit., p. 319.

(35) T. Ortiz, ob. cit., p. 320.

(36) T. Ortiz, ob. cit., p. 323. 
Abolida la constitución del año tercero, la historia de la Revolución entra en su etapa final. Se promulga una nueva constitución que conservaba las formas republicanas y creaba un consejo de tres personas con el título de cónsules, cuyas funciones duraban diez años, un senado conservador y un cuerpo legislativo.

Los tres cónsules nombrados fueron Bonaparte, Cambacérès y Lebrun. Bonaparte se apoderó de las riendas del gobierno, abrogó muchas leyes revclucionarias y ejerció sin obstáculos la autoridad absoluta $\left({ }^{37}\right)$.

Napoleón consiguió pacificar las provincias levantadas, restableció la religión católica y prosiguió el esfuerzo bélico en Italia, ocupando diversas ciudades, llevó a cabo la campaña del Rin y firmó varios tratados con Nápoles, Rusia, Turquia y otros países.

Finalmente el autor relata con precisión el papel desempeñado por Inglaterra en su lucha contra la Francia revolucionaria, y la situación de Holanda, Suiza, Italia y Santo Domingo.

La figura de Napoleón Bonaparte cierra el análisis de la Revolución francesa. Tras haber eliminado a los miembros del cuerpo legislativo, Bonaparte fue nombrado cónsul perpetuo, ampliando sus facultades para firmar tratados, disminuir las penas impuestas por los tribunales, teniendo gran influjo en las asambleas electorales. En estos años fueron agregados a Francia la Isla de Elva, el Piamonte y el Ducado de Parma $\left({ }^{38}\right)$.

Tras la paz de Amiens. se intentó restablecer a los Borbones en el poder. Desterrado el general Moreau, un destacamiento francés, violando el territorio de Baden, se apoderó del duque de Engheim, que fue pasado por las armas: «Este atentado, hijo de la violencia y de la ira, y no de la política, fue el primer acto que desacreditó a Bonaparte» $\left({ }^{39}\right)$.

Fracasada la conspiración de Moreau, el Senado le incitó a ceñirse la corona imperial. Medida que sólo contó con la oposición de Carnot y fue aprcbada en el Tribunado y en el cuerpo legislativo. El 18 de mayo de 1804 fue proclamado emperador de los franceses, y el 2 de diciembre ungido como tal por el sumo pontífice Pío VII.

Con ello acababa la Revolución y se abría un nuevo periodo de consolidación de la burguesía, bajo la mentalidad pragmática de Bonaparte:

(37) T. Ortiz, ob. cit., pp. 323-324.

(38) T. Ortiz, ob. cit., pp. 331-332.

(39) T. Ortiz, ob. cit., p. 334. 


\title{
La Revolución Francesa en la Obra de Tomas Ortiz
}

\begin{abstract}
"Este año acabó la revolución de ideas, y solo quedaron de ella los intereses materiales representados por el gobierno de Bonaparte y por la aritocracia que él había creado. La nueva constitución imperial destruyó enteramente la libertad de la prensa y la publicidad de la tribuna: sustituyó a tantas convulsiones y movimientos el amor de la gloria militar y el despotismo de un guerrero. El cansancio de la anarquia revolucionaria había preparado los ánimos a este resultado: Bonaparte tuvo el mérito egoista de haver conocido la disposición de las cosas y de haberse atrevido a la soberanía. No quiso trabajar por la libertad, en la cual no creía, ni por la dinastía legítima, que le hubiera reducido a la gloria modesta que se tributa al virtuoso Monk. Se creyó superior a su siglo, y se propuso dominarlo" $\left({ }^{40}\right)$.
\end{abstract}

La descripción que hace Tomás Ortiz de la Revolución francesa va más allá de la enumeración de unos hechos centrados en los personajes más importantes, como Luis XVI, Robespierre, Danton o Napoleón. Su objetivo, como hemos podido comprobar, es delimitar las distintas etapas del proceso revolucionario y su componente social predominante en cada una de ellas. Llama la atención la claridad en su exposición, que resume con estas palabras: «El poder - dice - pasó durante la revolución, del trono a la clase media en 1789, a la plebe en 1792; otra vez a la clase media en 1794; a la aristocracia en 1799 , y a la fuerza militar en 1804, la cual lo conservó hasta que se arruinó por sus propios e inevitables excesos» $\left({ }^{41}\right)$.

Sin embargo el texto no hace referencia alguna a la influencia de las ideas ilustradas, como motor ideológico de la Revolución, ni a sus consecuencias sociales y económicas o sus repercusiones en otros países.

Nos encontramos ante una exposición sumaria de la Revolución francesa, considerada ccmo el acontecimiento más importante de la historia moderna, adaptada a un nivel de enseñanza elemental. Aunque el autor no cita las fuentes utilizadas, su exposición sobre la Revolución rompe el esquematismo y simplismo utilizado frecuentemente en los manuales de la época. Por otra parte destaca el número de páginas empleadas en la redacción de este capítulo, similar al capítulo dedicado a Egipto, Grecia y Roma. El sistema expositivo utilizado, a base de preguntas y respuestas, cumple - como hemos indicado - un objetivo básico: señalar al alumno los contenidos más sobresalientes de la temática analizada.

(40) T. Ortiz, ob. cit., pp. 334-335.

(41) T. Ortiz, ob. cit, p. 335. 
Si tenemos en cuenta los libros de texto al uso y el estado de la enseñanza en España durante el primer tercio del sigla XIX, la orientación de la obra de Tomás Ortiz marca un hito importante dentro de las nuevas corrientes didácticas que se introdujeron tras el Trienio Liberal en las llamadas casas de educación. Prueba de ello es que la obra de Tomás Ortiz fue elegida, junto con las de V. Verdejo, Escosura, Ranera y el médico catalán Felip Monlau, por la comisión encargada de seleccionar los libros de texto, en la que colaboró Juan Nicasio Gallego ${ }^{\left({ }^{4}\right.}$ ).

(42) M.a del C. Simón Palmer, ob. cit., p. 107. 